\title{
Macleaya cordata Extract as an Ethnoveterinary Alternative for Broilers Challenged with Salmonella typhimurium
}

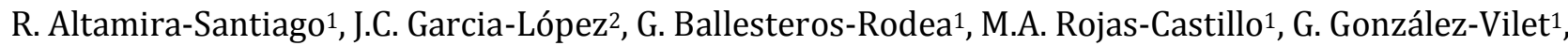 \\ N. Rios-Sanchez ${ }^{1}$, S. López-Aguirre ${ }^{1, *}$ \\ ${ }^{1}$ Faculty of Agronomy and Veterinary Medicine, Autonomous University of San Luis Potosí, San Luis Potosí - 78000, Mexico. \\ ${ }^{2}$ Desert Zone Research Institute, Autonomous University of San Luis Potos, San Luis Potosí - 78000, Mexico.
}

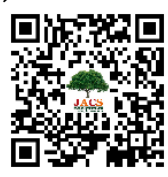

\section{A R T I C LE DET A I L S}

Article history:

Received 12 January 2021

Accepted 11 February 2021

Available online 19 February 2021

\section{Keywords:}

Colony Forming Units

Growth Promoter

Productive Parameters
A B S T R A C T

In order to evaluate the ethnoveterinary effect of Macleaya cordata extract on bacteria colony forming units (CFU) in different organs of gastrointestinal tract and productive parameters of broilers challenged with Salmonella typhimurium, eighty one day old Cobb broilers were randomly assigned either to a diet without additive or with additive at $50 \mathrm{~g} /$ ton during 21 days. The count of CFU of Salmonella typhimurium in crop, gizzard, and duodenum, at 21 days, showed broilers that received the Macleaya cordata extract had a reduction. The broilers also had higher final body weight, total gain, average daily gain and better feed conversion value as compared with those that had not received it. Feed intake was not affected. Results concluded that Macleaya cordata extract is an ethnoveterinary alternative efficient for control of Salmonella typhimurium and a growth promoter in broilers.

\section{Introduction}

In the poultry industry, chicks are the most susceptible to salmonella infections, by the exposition from hatchery, to broiler house [1]. Salmonella colonizes the intestinal tract, causing inflammation and high mortality in chicks less than 2 week age [1,2]. It is considered one of the most expensive diseases in broiler [3]. Macleaya cordata has been used as traditional Chinese medicine for specific purposes, modifies the immune system, reduce the inflammation, and has the capacity to inhibit the proliferation of bacteria, fungi, and viruses [4,5]. Ascribed these properties to the quaternary benzo[c]phenanthridine alkaloids, sanguinarina and queleritrina [6,7] may improve the absorption of nutrients $[8,9]$. The effects of the components of this plant could help the brolier's immune system to inhibit the growth of salmonella in the gastrointestinal tract, reduce inflammation of the intestine and improve the absorption and conversion of nutrients from feed. The aim of the present study was to evaluate the ethnoveterinary effect of Macleaya cordata extract on bacteria colony forming units (CFU) in different organs of gastrointestinal tract and productive parameters of broilers challenged with Salmonella typhimurium.

\section{Experimental Methods}

\subsection{Methods}

A Bioethics Committee reviewed and supervised that all the procedures with broilers, were realized in accordance with the Official Mexican Regulations on Technical Specifications in the Production, Maintenance, and Use of Laboratory Animals.

\subsection{Animals}

Eighty one day old Cobb broilers were housed in a temperaturecontrolled room $\left(25^{\circ} \mathrm{C}\right)$ and 24 hour light cycle. Eight brooder battery cages were used (Petersime Inc., Gettysburg, $\mathrm{OH}$ ) with 10 chicks per cage. At the beginning of the experiment, six chickens were sacrificed and crop, duodenum and gizzard samples were collected to verify the absence of Salmonella.

\subsection{Feeding}

From day one to day 21 old, chicks were fed a starter concentrate (Pollitos G.F. Purina, México). Four cages were randomly assigned feed without additive ( $0 \mathrm{~g} /$ ton) and four cages with additive (50 g/ton). The Macleaya cordata extract called Sangrovit ${ }^{\circledR}$ (Phytobiotics, Eltville, Alemania) was added on top of the concentrate. Broilers had free access to concentrate and fresh water.

\subsection{Salmonella typhimurium Challenge}

To test the ethnoveterinary effect of Macleaya cordata extract, a standard suspension of S. typhimurium (ATCC 14028) serotype B was prepared to meet the $0.5 \mathrm{Mc}$ Farland standard equivalents to $10^{8} \mathrm{CFU} / \mathrm{mL}$ concentration [10]. It was administered orally via an esophageal cannula at two and six days of the experiment [11].

\subsection{Productive Assay}

Growth evaluation lasted 21 days. Broilers were weighed daily. Body weight changes were recorded and average daily gain (AGD) was calculated. The feed intake was measured with the difference between the weights of concentrate offered minus the weight of concentrate refused (FI). Feed conversion ratio (FCR) was calculated as FI/ADG. At the end of productive assay, broilers were slaughtered by the electrical stunning method and afterwards bled [12].

Using sterile scissors, a small (approximately $1.5 \mathrm{~cm}$ ) hole was cut for the Colony Forming Units (CFU) count from the crop, duodenum, and gizzard. Two milliliters of sterile PBS were pipetted into each organ and two to four $\mathrm{mL}$ of suspension was recovered. The colony counting procedure used was the membrane filter technique [13]. A sample of CFU was collected and differential biochemical tests were performed according the PROY-NOM-210-SSA1 to verify that the isolated organism corresponded to salmonella.

\subsection{Data Analysis}

A complete randomized design was used to assess the extract activity for the experimental study. Bacterial numbers were converted to log CFU for statistical analysis. The analysis of variance was performed with PROC GLM of SAS and Tukey means with SAS Institute software [14]. 


\section{Results and Discussion}

The count of colony forming units of Salmonella typhimurium in crop, gizzard and duodenum (Table 1$)$ decreased $(\mathrm{P}<0.05)$ in broilers fed with diet added with Macelaya cordata extract. At 21 days, higher final body weight, total gain, average daily gain and better feed conversion value were found compared to broilers that did not receive it (Table 3). Feed intake was not affected $(\mathrm{P}>0.05)$.

Table 1 Effect of Macleaya cordata extract on count of colony forming units [log $\mathrm{CFU} / \mathrm{mL}$ in different organs of broilers

\begin{tabular}{llll}
\hline Organs & \multicolumn{2}{l}{ Macleaya cordata extract g/ton } & SEM \\
\cline { 2 - 3 } & 0 & 50 & 0.031 \\
\hline Crop & $2.30^{\mathrm{a}}$ & $1.60^{\mathrm{b}}$ & 0.018 \\
Gizzard & $2.19^{\mathrm{a}}$ & $1.38^{\mathrm{b}}$ & 0.007 \\
Duodenum & $2.07^{\mathrm{a}}$ & $1.09^{\mathrm{b}}$ & \\
\hline
\end{tabular}

SEM: standard error of means, a,bMeans in a row with different superscripts are different at $P<0.05$

Table 2 Results of the biochemical tests applied to the isolated microorganism

\begin{tabular}{llll}
\hline Parameter & Presence & Parameter & Presence \\
\hline D Glucose & + & Fermentation glucose & + \\
$\mathrm{H}_{2}$ S Production & + & L Lactate alkalinization & + \\
Citrate sodium & + & D maltose & + \\
D mannitol & + & D sorbitol & + \\
Beta-galactosidase & - & L-arabinol & - \\
D-cellobiose & - & B-glusosidae & - \\
Urease & - & Decarboxylase base & -
\end{tabular}

Correspondence to microorganism Salmonella typhimurium

Antibiotics added in broilers diet can be replaced with ethnoveterinary alternatives. In this case, isoquinoline alkaloids from Macleaya cordata has different functions. They promote immune functions that can activate phagocytosis, regulating haptoglobin and amyloid $\mathrm{A}$, as well as, prompt defensive reactions by the immunological system of broiler $[15,16]$. Reducing the inflammation and alleviating the injury of gastrointestinal mucosa [4], prevents the spread of bacteria [17]. These combined effects could explain the decrease in the CFU count of Salmonella typhimurium in the gastrointestinal tract of broilers that received the extract.

Table 3 Effect of Macleaya cordata extract on productive parameters of broilers challenged with Salmonella typhimurium

\begin{tabular}{llll}
\hline Parameter & \multicolumn{2}{l}{ Macleaya cordata extract g/ton } & \multicolumn{2}{c}{ SEM } \\
\cline { 2 - 3 } & 0 & 50 & 0.72 \\
\hline Initial body weigth (g) & $51.9^{\mathrm{a}}$ & $50.8^{\mathrm{a}}$ & 4.32 \\
Body weigth at 21 d (g) & $376.1^{\mathrm{b}}$ & $440.3^{\mathrm{a}}$ & 0.56 \\
Total gain (g) & $324.2^{\mathrm{b}}$ & $389.5^{\mathrm{a}}$ & 0.04 \\
Average daily gain (g) & $16.29^{\mathrm{b}}$ & $18.54^{\mathrm{a}}$ & 0.31 \\
Feed intake (g/d) & $52.14^{\mathrm{a}}$ & $52.28^{\mathrm{a}}$ & 0.02 \\
Feed conversion ratio & $3.20^{\mathrm{a}}$ & $2.81^{\mathrm{b}}$ &
\end{tabular}

SEM: standard error of means, a,bMeans in a row with different superscripts are different at $P<0.05$

The diseases by enteric bacteria entails first, the colonization of the intestinal mucus, then it joins the epithelium and penetrates into the underlying layer $[18,19]$. It can be affected the enterocytes that are involved in the final stages of digestion, transport and nutrient absorption $[20,21]$. However, it was found that the biocompounds of plants, can modulate the fluidity and permeability of the cell membrane, improving the absorption of nutrients [22]. This can explain the improvement in the productive parameters found in our experiment. The present findings agree with other authors who reported that ingested isoquinoline alkaloids at the dose of 25 and $50 \mathrm{ppm}$, the body weight and feed conversion rate increased $[23,24]$.

\section{Conclusion}

According to our results, it can concluded that Macleaya cordata extract is an efficient ethnoveterinary alternative for control of Salmonella typhimurium and promotes growth in broilers.

\section{References}

[1] K.M. Wilson, D.V. Bourassa, A.J. Davis, M.E. Freeman, R.J. Buhr, The addition of charcoals to broiler diets did not alter the recovery of Salmonella Typhimurium during grow-out, Poultry Sci. 95 (2016) 694-704.

[2] Y.O. Fasina, P.S. Holt, E.T. Moran, R.W. Moore, D.E. Conner, S.R. McKee, Intestinal cytokine response of commercial source broilerchicks to Salmonella typhimurium infection, Poult. Sci. 87 (2008) 1335-1346.

[3] F.P. Calenge, A. Kaiser, C. Vignal, A. Beaumont, Genetic control of resistance to salmonellosis and to Salmonella carrier-state in fowl: a review, Genet. Select. Evol. 42 (2010) 1-11.

[4] H. Ni, Y. Martínez, G. Guan, R. Rodríguez, D. Más, et al., Analysis of the impact of isoquinoline alkaloids, derived from Macleaya cordata extract, on the development and innate immune response in swine and poultry, BioMed. Res. Int. 2016 (2016) 1352146:1-7.

[5] K. Šedo, P. Vlašicová, R. Barták, J. Vespalec, V. Vičar, et al., Quaternary benzo[c]phenanthridine alkaloids as inhibitors of aminopeptidase $\mathrm{N}$ and dipeptidyl peptidase IV, Phytother. Res. 16(1) (2001) 84-87.

[6] Z. Ming, L. Gui-yin, Z. Jian-guo, Z. Li, H. Ke-long, et al., Evaluation of molluscicidal activities of benzo[c]phenanthridine alkaloids from Macleaya cordata (Willd) R. Br. on snail hosts of Schistosoma japonicum, J. Med. Plant. Res. 5(4) (2011) 521-526.

[7] V. Simanek, R. Vespalec, A. Sedo, J. Ulrichova, J. Vicar, Quaternary benzo[c]phenanthridine alkal oids - biological activities, in: Chemical Probes in Biology, M.P. Schneider, (Ed.), Vol. 129 of NATO Science Series II, Mathematics, Physics and Chemistry, Kluwer Academic, Dordrecht, The Netherlands, 2003, pp.245-254.

[8] L. Li, F. Yin, B. Zhang, H. Peng, F. Li, et al., Dietary supplementation with Atractylodes macrophala Koidz polysaccharides ameliorate metabolic status and improve immune function in earlyweaned pigs, Livestock Sci. 142(1) (2011) 33-41.

[9] G. Liu, G. Guan, J. Fang, Y. Martínez, S. Chen, et al., Macleaya cordata extract decreased diarrhea score and enhanced intestinal barrier function in growing piglets, BioMed. Res. Int. 2016 (2016) 1069585:1-7.

[10] M. Koller, P. Hesse, A. Salerno, A. Reiterer, G. Braunegg, A viable antibiotic strategy against microbial contamination in biotechnological production of polyhydroxyalkanoates from surplus whey, Biomass Bioenergy 35 (2011) 748753.

[11] E.E. Koneman, D.S. Allen, V.R. Dowell, W.M. Janda, H.M. Sommers, W.C. Winn Diagnostic microbiology, $5^{\text {th }}$ Edn., Lippincott, United States, 1997.

[12] EFSA, European Food Safety Authority, Welfare aspects of the main systems of stunning and killing the main commercial species of animals, EFSA Journal 45 (2004) 1-29.

[13] J.M. Pelczar, D.R. Reid, Microbiology, McGraw-Hill Book Company, Inc. New York, Toronto, London, 1958

[14] SAS Institute, SAS/STAT User's Guide, Version 9.1 for Windows, SAS Inst. Inc., Cary, NC., 2004.

[15] W. Windisch, K. Schedle, C. Plitzner, A. Kroismayr, Use of phytogenic products as feed additives for swine and poultry, J. Ani. Sci. 86(14) (2008) E140-E148.

[16] D. Gudev, S. Popova- Ralcheva, P. Moneva, M. Bonovska, G. Valchev, A. Valcheva. Effect of supplemental Sangrovit on some biochemical indices and leukocytes phagocytic activity in growing pigs, Arch. Zootech. 7 (2004) 123-134.

[17] G.B. Mahady, S.L. Pendland, A. Stoia, L.R. Chadwick, In vitro susceptibility of Helicobacter pylori to isoquinoline alkaloids from Sanguinaria canadensis and Hydrastis canadensis, Phytother. Res. 17 (2003) 217-221.

[18] B. Opitz, S. Hippenstiel, J. Eitel, N. Suttorp, Extra- and intracellular innate immune recognition in endothelial cells, Thromb. Haemost. 98 (2007) 319326.

[19] G. Hecht, Innate mechanisms of epithelial host defense: spotlight on intestine, Am. J. Physiol. 277 (1999) 351-358.

[20] C.S. Potten, M. Loeffler, Stem cells: attributes, cycles, spirals, pitfalls and uncertainties. Lessons from the crypt, Development 110 (1990) 1001-1020.

[21] D.H. Scoville, T. Sato, X.C. He, L. Li, Current review: Intestinal stem cells and signaling, Gastroenterol. 134 (2008) 849-864.

[22] A.A. Amad, K. Manner, K.R. Wendler, K. Neumann, J. Zentek, Effects of a phytogenic feed additive on growth performance and ileal nutrient digestibility in broiler chickens, Poultry Sci. 90 (2011) 2811-2816.

[23] S.L. Vieira, O.A. Oyarzabal, D.M. Freitas, J. Berres, J.E.M. Peña, et al., Performance of broilers fed diets supplemented with sanguinarine-like alkaloids and organic acids, J. Appl. Poult. Res. 7(1) (2008) 128-133.

[24] A.M. Abudabos, H.A. Abdullah, Y.M. Dafalla, R.U. Khan, The effect of phytogenic feed additives to substitute in-feed antibiotics on growth traits and blood biochemical parameters in broiler chicks challenged with Salmonella typhimurium, Environ. Sci. Pollut. Res. Int. 23(23) (2016) 24151-24157. 